DR. SVEN SEYS (Orcid ID : 0000-0002-4399-9892)

DR. BENOIT PUGIN (Orcid ID : 0000-0001-7132-9477)

Article type : Original Article: Airway Diseases

\title{
Mobile health tools for the management of chronic respiratory diseases
}

\section{Authors:}

Kristien Sleurs ${ }^{1, *}$, Sven Seys ${ }^{2,3, *}$, Jean Bousquet ${ }^{4}$, Wytske Fokkens ${ }^{5}$, Senne Gorris ${ }^{1}$, Benoit Pugin $^{2,3}$, Peter W. Hellings $1,2,3,5$

\section{Affiliations:}

1 - Department of Otorhinolaryngology, University Hospitals Leuven, KU Leuven, Leuven, Belgium

2 - Department of Microbiology and Immunology, Laboratory of Clinical Immunology, KU Leuven, Leuven, Belgium

3 - EUFOREA, European Forum for Research and Education in Allergy and Airway Diseases, Brussels, Belgium

4 - Department of Respiratory Disease, University Hospital Arnaud de Villeneuve, Montpellier, France

5 - Department of Otorhinolaryngology, Academic Medical Center, Amsterdam, The Netherlands

*Shared first authors. These authors contributed equally to the manuscript.

This article has been accepted for publication and undergone full peer review but has not been through the copyediting, typesetting, pagination and proofreading process, which may lead to differences between this version and the Version of Record. Please cite this article as doi: $10.1111 /$ all.13720

This article is protected by copyright. All rights reserved. 


\title{
Corresponding author:
}

\author{
Peter W. Hellings \\ Department of Otorhinolaryngology, Head and Neck Surgery \\ University Hospitals Leuven, \\ Kapucijnenvoer 33, 3000 Leuven, Belgium \\ Phone: 00.32.16.33.23.42, Fax: 00.32.16.34.60.35 \\ E-mail: Peter.Hellings@uzleuven.be
}

\section{Keywords:}

Allergic rhinitis, asthma, chronic rhinosinusitis, mobile application, patient empowerment, self-management

\section{Highlights:}

- Over 100 mobile applications were identified that support patients with chronic respiratory diseases via self-monitoring, personalized feedback and/or patient education.

- A newly designed 'patient empowerment index through mobile technology' was developed to support patients and physicians in respectively choosing or recommending mobile applications for the patients' self-management of the disease.

\begin{abstract}
Background: The market of mobile health (mHealth) technology is rapidly evolving, making new mobile technologies potentially available for health care systems. Patient empowerment through self-monitoring of symptoms, shared decision making with the physician and easily accessible education are important features extending the reach of mHealth technology beyond traditional care.

Methods: Two digital distribution platforms (Apple App Store and Google Play Store) were searched for currently available mobile applications (apps) for patients with chronic respiratory diseases (CRDs). A new index (score ranging from 0-10) was developed to assess the potential of apps as a tool to empower patients through mobile technology (based on selfmonitoring, personalized feedback and patient education app features).
\end{abstract}

This article is protected by copyright. All rights reserved. 
Results: One hundred and twelve apps were retained for analysis and could be classified in 5 categories: Asthma ( $n=71)$, COPD $(n=15)$, Asthma and COPD $(n=15)$, Rhinitis and Asthma $(\mathrm{n}=5)$ and Rhinosinusitis ( $\mathrm{n}=6)$. Eighty percent were developed by medical technology companies compared to $18 \%$ by medical doctors and $2 \%$ by pharmaceutical companies. Twothirds of apps allow disease self-monitoring whereas over half of apps provide patient feedback through graphs. Sixty percent of apps contain easily accessible patient education material. Only sixteen percent of apps reach a score of $\geq 7$ on the newly designed patient empowerment index.

Conclusions: A variety of apps are available for patients with CRDs of which only few were developed by or jointly with medical doctors. The majority of these apps include selfmonitoring tools but only few also provide personalized feedback, which is needed to adopt these apps into daily care.

\section{INTRODUCTION}

'Technology made large populations possible; large populations now make technology indispensable.'- Joseph Wood Krutch (1)

Technology and big data are changing every aspect of our daily functioning, including healthcare. With worldwide daily improvements in artificial intelligence and the majority of people having a piece of 'mobile' technology with them at all times, we are on the verge of a digital revolution across every aspect of the healthcare sector. For healthcare professionals this presents an enormous challenge staying up to date and keeping score of which technology will help HCPs and their patients in daily practice. Medical innovation provides a significant opportunity: the amount of available data and variables of each patient increases tremendously and, used to their advantage, can lead to new, improved and more holistic solutions that may lead to better outcomes and help to reduce the burden of chronic illnesses. Mobile health (mHealth) technologies can be used to upscale and democratize the research process in order to optimize diagnostic and therapeutic strategies solutions by helping the medical community reach previously underserved and understudied groups of people (2).

Medical mobile apps are expected to benefit not only researchers in providing real-life data, but affect all stakeholders in health care in many ways, as is shown in Figure E1 (3). From the patients' perspective, mHealth technologies have the potential to involve patients as active partners in the management of their disease and as such increase the level of patient

This article is protected by copyright. All rights reserved. 
empowerment (4,5). Such shared and informed decision making requires access to easily understandable information about the disease and treatment options for which digital tools are well placed $(4,6)$. Additionally, mHealth technologies can encourage patients to improve adherence to treatment by reminding them to take their medication, register medication intake and improve understanding of the therapeutic plan. Despite high expectations of these technologies, the degree of adoption of app features that will contribute to patient empowerment remains largely unexplored in the field of chronic respiratory diseases (CRDs).

From the physician's perspective mHealth technology provides tools that help patients to monitor the evolution of their disease and triage patients to make sure that those who need further investigations will be alerted (7). In addition, mHealth tools allow stratification of patients into disease phenotypes that do or do not benefit from specific treatments based on co-morbidities, life-style factors and other person-related factors (3). Finally, health care systems benefit from remote monitoring of chronic diseases, as this may lead to a reduction of unnecessary consultations and hospitalizations, resulting in a decrease in health care costs (8).

Chronic respiratory diseases (CRDs) are associated with a high burden for patients and society in terms of reduced Quality of Life (QoL) and high economic costs (9). It is estimated that over 300 million of people worldwide suffer from asthma (10). Despite current treatment modalities, a subgroup of $10-15 \%$ of adult patients still has uncontrolled asthma with persisting symptoms and increased risk of exacerbations, hospital admissions, major absenteeism and death (11-13). Currently 64 million people worldwide have COPD and it is predicted to become the third leading cause of death worldwide by 2030 (14). Allergic rhinitis (AR) affects up to $30 \%$ of the European population with up to $35 \%$ of patients being uncontrolled after pharmacotherapy, which is associated with a high costs for society (1719)(15-17). Chronic rhinosinusitis (CRS) affects 5-13\% of the general population and is associated with nasal polyps in up to $60 \%$ of patients (20-22)(18-20). Amongst CRS patients undergoing endoscopic sinus surgery in an academic center, 40\% remain uncontrolled 3-5 years post-surgery (21) and there is a clear correlation between CRS severity and asthma related systemic corticosteroid use (22). Managing these CRDs thereby forms a major challenge for patients, health care providers and health care systems.

This manuscript reports on an exhaustive search for mHealth apps currently available for asthma, COPD, rhinitis and rhinosinusitis. We here aim to provide physicians with an overview of the features and shortcomings of the currently available apps and as such support

This article is protected by copyright. All rights reserved. 
them in selecting mHealth tools that could be advised to their patients. A new index for evaluation of the degree of patient empowerment of mHealth tools was designed.

\section{METHODS}

\section{Screening and selection of the applications}

Currently, the two largest global platforms for app distribution with the most diverse target population are 'Google Play Store (Android apps)' and the 'Apple App Store (iOS apps)'. These two platforms were screened for apps using the search terms "asthma", "COPD" (only the acronym was used as a search term), "rhinitis" or "rhinosinusitis".

Inclusion criteria: Apps running on Android and/or iOS, being available for free or paid, and available at least in English (some apps include additional languages).

Exclusion criteria: Apps that only offer research articles, publications, congress information, protocols or guidelines or calculators for medical formulae for physicians, medical students, nurses and other medical professionals were excluded. Apps that only give geographic information about air quality and/or pollen count were excluded. Apps with focus on general health, including diseases such as hypertension and diabetes, were excluded. Apps offering non-evidence-based treatment advice such as herbs and oils, massage, acupuncture, yoga promotion and breathing exercises. Finally, apps containing breathing games designed for kids to become more relaxed were excluded.

\section{Assessment of apps}

App characteristics and functionalities were evaluated based on information available in the digital distribution platforms (App Store and Play Store) or on the websites of the apps.

First of all, apps were assessed for a series of basic characteristics: platform, app developer, downloading cost, language and date of last update.

Secondly apps were checked for the presence of tools for self-monitoring of disease, personalized feedback and self-education material. Self-monitoring of disease in apps includes subjective evaluation of disease control, objective evaluation of disease-related parameters (i.e. lung function), registration of medication use (i.e. inhaler use), collecting information on environmental exposure and real-time assessment of activity level. The type

This article is protected by copyright. All rights reserved. 
of personalized feedback on disease control and disease progression in apps was assessed for the following items: feedback through diaries, graphs and/or charts; action plans (AP) for disease management and/or reports shared with their health care providers; reminders for taking medicines and/or recording symptoms through the app.

Finally, the educational part of the apps was evaluated in terms of content type (i.e. text-form and/or videos) and the coverage of the topic (i.e. basic facts about disease, basic principles of treatment, trigger avoidance, correct use of inhalers and managing of exacerbations).

\section{Development of the 'patient empowerment through mobile technology index'}

Given the large number of mHealth apps, there is need for a scoring system to assist patients and health care providers in choosing an app that fully supports self-management of the patients' chronic condition. So far, there is no validated scoring system available to assess the level patient empowerment of apps. According to the definition of Funnell et al. patients are empowered when they have knowledge, skills, attitudes, and self-awareness necessary to develop the capacity to be responsible for their own lives and influence their own behaviour in order to improve the quality of their lives (23). The conceptual model of Bravo et al. was used to evaluate the specific elements that were used in the index to assess patient empowerment by use of mobile technology (4). The three key elements (self-monitoring, personalized feedback and patient education) are critical in this model and identified as indicators of patient empowerment. As such we considered the app functionalities 'selfmonitoring', 'personalized feedback' and 'patient education' as key features to empower patients through mobile technology. The scoring system is therefore called 'patient empowerment through mobile technology index'. A similar weight was given to each of the sub-items belonging to self-monitoring, personalized feedback and patient education. Details about the scoring system can be found in Table 1 .

\section{RESULTS}

Searches performed in November 2017 identified 314 apps $(n=232$ Android; $n=174$ iOS) for CRDs. After applying exclusion criteria, 112 apps $(n=86$ Android; $n=61$ iOS; $n=35$ both platforms) were retained for further analysis. These apps can be classified in 5 categories: Asthma ( $n=71)$, COPD $(n=15)$, Asthma and COPD $(n=15)$, Rhinitis and Asthma $(n=5)$ and Rhinosinusitis $(n=6)$. Figure 1 illustrates the app selection process. A detailed

This article is protected by copyright. All rights reserved. 
overview of the app characteristics, self-monitoring, patient feedback and patient education functionalities can be found in Table 2 .

\section{App characteristics}

Eighty percent of the apps were created by Medical Technology (Medtech) companies (Figure 2B). Medical doctors were involved in the development process of $18 \%$ of the apps and only 2 of apps were developed by a Pharmaceutical company. About half of the selected apps had their update performed in 2017 (Figure 2C). The bulk of apps were available for free (Figure 2E). Most apps were only available in English whereas one fourth were also available in additional languages (Figure $2 \mathrm{~F}$ ).

\section{Self- monitoring}

Of the included apps, two-thirds can be used for self-monitoring of either disease control, medication use and/or environmental exposure or physical activity (Figure 3A). Disease control is evaluated subjectively using validated Patient-Reported Outcome Measures (PROMs) such as Asthma Control Test (ACT), COPD assessment test (CAT) or Control of Allergic Rhinitis and Asthma Test (CARAT) in 14\% of the apps (Table 1). Evaluation of disease symptoms by tapping on a button, checking off a list, moving a slider or choosing a smiley to indicate disease severity, as is shown on screenshots in Figure E2, is found in 38\% of the apps. Twenty percent of the apps have the possibility to connect wireless devices such as peak flow meters and/or inhaler sensors, as is shown on screenshots in Figure E3. These systems allow objective evaluation of disease-related parameters such as lung function, or registration and tracking of inhaler use. Daily information about a patient's environment including air quality and pollen count is offered in $12.5 \%$ of the apps. Only $6 \%$ of the selected apps track physical activity.

\section{Patient feedback}

Recorded data are compiled in diaries, or presented on graphs or charts in more than half of the apps as is shown in Figure 3B and E2. This allows patients to interpret the results, identify critical periods, spot trends over time and understand associations between tracked parameters. Reports including diaries, graphs and charts can be shared with health care 
providers, via printing, e-mail or through a QR-code system. Only $11 \%$ of the apps provide feedback via an action plan (AP) for asthma or COPD. Personal reminders for taking medication are integrated in one fourth and alerts for recording of symptoms in $13 \%$ of the self-monitoring apps.

\section{Patient education}

Sixty percent of the apps contain easily accessible self-education material (Figure 3C). All of these apps contain written information in the format of short texts, with $13 \%$ of the apps providing educational videos. About one-third of the apps give information on basic facts of disease and a similar number of apps contain information on basic principles of treatment. In $20 \%$ of the apps tips for avoiding disease triggers are offered. Tips for correct use of inhalers are presented in $10 \%$ of the apps and tips for the management of acute exacerbations are offered by $16 \%$ of the apps.

\section{Patient empowerment through mobile technology index}

The patient empowerment through mobile technology index was calculated for all included apps (Table 2). The index was highly variable amongst the different apps with $51 \%$ of apps having a score of 3 or lower, 33\% have a score between 4 and 6 and $16 \%$ of apps reached a score of 7/10 or higher: Respitrack, My Breathefree, Asthma-Info, Asthma Tracker, AAP Asthma Tracker for Adolescents, Signs \& symptoms Asthma, E-symptoms and My COPD Manager, Propeller Health, AsthmMD, Kiss my Asthma, My Asthma Manager, Conolly Asthma App, Advocade Asthma app, Asthma Action Hero, 7 keys to manage Child Asthma and MyAllergyDiary and mySinusitisCoach (Figure 4).

\section{DISCUSSION}

A systematic search in the two most widely used public digital distributions platforms revealed 112 apps that are potentially useful in guiding patients with CRDs in selfmanagement of their disease. Most of these apps were developed for patients with asthma but several apps are covering more than 1 disease. The ultimate goal of adoption of mHealth tools in disease management of CRD patients is to reach better patient outcomes, including quality of life. This can only be achieved if these tools are designed and developed in such a

This article is protected by copyright. All rights reserved. 
way that patient empowerment is maximized (4). Firstly, self-monitoring and personalized feedback allow patients to manage their disease more autonomously, being less dependent on health care workers, and feel more responsible for controlling their disease. Secondly, patient education will allow patients to improve their health literacy and thereby enable them to make better informed decisions about their health.

Two-thirds of the evaluated apps provide patient feedback via a graph visualizing the degree of symptoms over time, whereas only $10 \%$ of apps provide patient feedback through an action plan (AP). Self-management, including self-monitoring of symptoms and/or lung function with patient feedback through an individualized written AP, has been advocated for many years for patients with asthma $(24,25)$. A systematic meta-review of supported selfmanagement tools for asthma now confirms its effectiveness without increase of total healthcare costs (26). Assembling self-monitoring data through mobile phone- and internetbased self-management programs has also been demonstrated to improve asthma control, lung function and QoL in asthma patients (29-31)(27-29). Similar conclusions were drawn from 2 other systematic reviews of smartphone interventions on the level of COPD exacerbations and hospitalizations (32-34)(30-32).

So far no evidence is available that mobile APs for the management of allergic rhinitis and chronic rhinosinusitis are improving clinical patient outcomes or are cost-effective, although two recently developed apps alert patients to take action when the patients' disease is uncontrolled $(33,34)$. More personalized feedback messages are needed in order to fully support patients in the day-to-day management of their disease. In addition, there is the need for real-life studies to demonstrate cost-effectiveness of such tools. These studies might include both implementation research or randomized sham-controlled trials with evaluation of patients using mHealth tools for disease management compared to standard of care.

Twelve percent of the apps included in the current study are able to import data from wireless devices for objective measurements of lung function. Apps that provide patient feedback based on information from smart sensors or monitoring devices integrated into one system, represent a new group of mHealth tools. The MyAirCoach project, is developing such an integrated system consisting of a user-friendly app for asthma patients (35). In this system several parameters are monitored, including lung function, fraction of exhaled nitric oxide (FeNO), exhaled breath temperature (EBT), respiratory rate (RR), physical activity and heart rate, medication adherence, pollen count and air quality (35). An ongoing trial aims to

This article is protected by copyright. All rights reserved. 
determine which of these devices and sensors can predict uncontrolled disease or asthma exacerbations.

Recent technological advances specifically allow monitoring of adherence to treatment through dose sensors but only very few mHealth tools have integrated this solution. In addition, apps have been developed. This was found in $25 \%$ of apps included in the current study. A trial in asthma patients demonstrated that reminders in the form of text messages and automated phone calls increased patient treatment adherence (36). In AR patients, internetbased tele-monitoring improved adherence to nasal corticosteroids treatment (37). These studies show that there is an opportunity for improving treatment adherence and clinical outcomes by integrating reminders into apps (38).

The quality of mHealth apps is determined by app usability and clinical proof of efficacy. There is currently no validated score available to evaluate mHealth app quality taking into account both points. A scoring system, so called the Mobile Application Rating Scale (MARS), has however been developed (39) and recently validated but targets the end user (40). This scoring system is insufficient to determine the overall quality, including clinical proof of efficacy. It is key for developers to create new technologies with a high usability as this will impact compliance to and long-term use of apps. Programs that take into account patient and HCP perspectives while developing mHealth tools are likely to have a positive impact on the usability of such tools (41). A recent study in AR patients using the Allergy Diary app also suggests good usability particularly through its simple and user-friendly design (7). Other examples point towards the complexity to reach adoption of apps in daily practice. Two studies with mobile phone- and internet-based interventions on physical activity and smoking cessation in COPD patients showed low adherence to the app, which might be due to the age of the study population or the well-known difficulties with smoking cessation $(42,43)$.

In addition to app usability, the potential of health apps to empower patients in selfmanagement of their disease is critical for the adoption of these apps in daily clinical practice. To that extent we have created the 'patient empowerment through mobile technology index'. Strikingly only $16 \%$ of apps reach an index score of 7 or above. Additional efforts of app developers are needed to improve existing health apps in order to be considered as tools for disease self-management by patients. The index could in future be used as a new tool for patients and physicians but therefore requires additional validation by a multi-disciplinary expert panel of patients, physicians, app developers and other mHealth experts.

This article is protected by copyright. All rights reserved. 
We found that medical doctors are involved in the development process in $18 \%$ of the apps by looking into digital distribution platform information and the app websites. Given the lack transparency on who is exactly involved in the development process of apps, it is possible that the real percentage is higher. In the context of patient empowerment, it would be extremely valuable that patients get involved in both the development and validation process of health apps. So far, as with involvement of medical doctors, the lack of transparence in the development process does not allow systematic evaluation of this. The perception that every person can launch medical applications, without detailed knowledge about the subject, raises concerns about validity and safety of educational content, diagnostic procedures and therapeutic suggestions. Huckvale et al. reported that half of the evaluated asthma apps provide information that is not supported by evidence or guidelines (44). Most apps available in public digital distribution platforms are not regulated by the Federal Drug Administration (FDA) or the European Medicines Agency (EMA). Recently in the United Kingdom (UK) the Medicines and Health care products Regulatory Agency (MHRA) set up a flowchart to help mHealth app developers and users to identify whether an app is a safe and operative medical device (45). This might be the first step towards a comprehensive European legislation for mHealth apps in order to exclude unsafe apps that have potential life-threating consequences.

Once an app has been optimized to maximize patient empowerment, several additional barriers need to be addressed in order to obtain full adoption of mHealth tools in clinical practice. Mobile apps collecting personal data have to comply with privacy regulations General Data Protection Regulation (GDPR) (46) - as well as with local laws. Strikingly, an analysis performed in 2014 showed that $30.5 \%$ of mobile health apps have included a privacy policy document and most require a high level of literacy (47). A Code of Conduct on privacy protection for mHealth apps is currently being developed (48) and may serve as a practical guide for developers to create apps corresponding to the European laws on security and privacy. Once this document is approved by the data protection authorities, these up-to-date rules can be applied in practice.

Secondly, apps need to be interoperable with existing health data exchange systems to allow health care providers to access, store or interpret the data collected through the app. Thirdly, evidence of clinical effectiveness of mHealth apps for CRDs is currently limited and requires well-designed clinical trials. Lastly, sustainability of the business model is a final but crucial aspect in order to achieve a tool that is credible and to be used over a long period of time. Cost-effectiveness studies will therefore be needed to convince policy makers and payers to

This article is protected by copyright. All rights reserved. 
imbed mHealth tools in the local health care system and reimburse those tools that fulfill all of the above-mentioned criteria.

The limitations of this manuscript are that the patient empowerment index requires further validation. Secondly, the intrinsic quality of the apps could not be assessed because of the lack of validated scoring systems.

\section{CONCLUSION}

An exhaustive search in the two largest digital distribution platforms identified 112 mobile applications for patients with CRDs. While many apps are available, the usability of these apps in clinical practice is hampered by several factors: lack of quality control, lack of evidence for clinical efficacy and cost-effectiveness and low degree of functionalities that maximize patient empowerment.

The large amount of data collected through mHealth apps is boosting healthcare research and innovation in the area of managing allergic rhinitis and asthma. It is expected that apps for other chronic respiratory diseases will follow the same direction. Such analyses will likely provide the required clinical and cost-effectiveness evidence for validation of mHealth apps and thereby facilitate its implementation in daily clinical practice. A WHO mHealth handbook on monitoring and evaluation of mHealth programs for non-communicable diseases is currently under construction and might guide future mHealth tool implementation into daily practice (source: http://www.who.int/ncds/prevention/be-healthy-bemobile/handbooks/en/).

To conclude, mHealth tools for patients with chronic inflammatory disease in future might look surprisingly similar. These patients all require tools for self-monitoring of symptoms and/or disease control, tools to improve therapy adherence, self-management action plans and patient educational materials. Ideally and in the context of co-morbidities, one mobile application with a similar bone structure supplemented with disease-specific material might be the way forward to reduce complexity and diversity of the current mHealth landscape for patients with chronic conditions (49-51).

This article is protected by copyright. All rights reserved. 


\section{FIGURE LEGENDS}

\section{Figure 1. Flowchart of app selection process.}

*:91 of the apps are available in both Android and Apple Stores; ${ }^{* *} 56$ of the excluded apps are available in both Android and Apple Stores; ${ }^{* * *} 35$ of the included apps are available in both Android and Apple Stores.

\section{Figure 2. Evaluation of app characteristics.}

A. Number of apps included for asthma, asthma and COPD, COPD, rhinosinusitis, rhinitis and asthma B. Percentage of apps developed by medical experts, medical technology companies and pharmaceutical industry C. Percentage of apps updated in 2017 and before 2017 D. Percentage of apps available for Android, iOS and both E. Percentage of apps for free and paid F. Percentage of apps in English and not-English languages.

\section{Figure 3. Evaluation of app functionalities.}

A. Number of apps that track inhaler use, environment, lung function, disease control and symptoms. B. Number of apps that provide an action plan, reminders for monitoring, reminders for medication use, possibility to share results with health care provider, graphs or charts. C. Number of apps that present information about inhaler technique, first aid, trigger avoidance, treatment and disease.

\section{Figure 4. Patient empowerment through mobile technology index.}

Apps were scored from 0 to 10 based on four criteria: basic characteristics, self-monitoring, personalized feedback and patient education. $16 \%$ of the apps scored $\geq 7,33 \%$ of the apps scored $4-6$ and $51 \%$ of the apps scored $\leq 3$. A list of the top 3 apps for each disease is presented in the table on the right.

This article is protected by copyright. All rights reserved. 


\section{TABLES}

Table 1. Overview of included apps stratified by disease area and ordered according the patient empowerment through mobile technology index.

\begin{tabular}{|c|c|}
\hline \multicolumn{2}{|l|}{ Patient empowerment through mobile technology index } \\
\hline \multicolumn{2}{|l|}{ Self-monitoring } \\
\hline Subjective evaluation of symptoms and/or disease control & 1 \\
\hline Tracking of medication intake & 1 \\
\hline Objective evaluation of lung function and/or inhaler use & 1 \\
\hline Real-time information about environment and/or physical activity & 1 \\
\hline \multicolumn{2}{|l|}{ Personalized feedback } \\
\hline Overview in diary, graphs or charts and/or share those with doctor & 1 \\
\hline Feedback through an action plan & 1 \\
\hline Reminders for medication intake and/or recording symptoms & 1 \\
\hline \multicolumn{2}{|l|}{ Patient education } \\
\hline Educational content in text & 1 \\
\hline Educational content in videos & 1 \\
\hline Educational content in quiz format & 1 \\
\hline
\end{tabular}

This article is protected by copyright. All rights reserved. 
Table 2. Patient empowerment using mobile technology index.

\begin{tabular}{|c|c|c|c|c|c|c|c|c|c|c|c|c|c|c|c|c|c|c|c|c|c|c|c|c|}
\hline & \multicolumn{5}{|c|}{ App characteristics } & \multicolumn{6}{|c|}{ Self-monitoring } & \multicolumn{5}{|c|}{$\begin{array}{l}\text { Personalized } \\
\text { feedback }\end{array}$} & \multicolumn{7}{|c|}{ Education } & \\
\hline $\begin{array}{l}\text { App } \\
\text { Name }\end{array}$ & $\begin{array}{l}\text { Upd } \\
\text { ate }\end{array}$ & Developer & 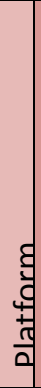 & 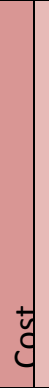 & $\begin{array}{l}0 \\
0 \\
\text { c } \\
0 \\
\text { c } \\
\text { त } \\
0\end{array}$ & ปี & 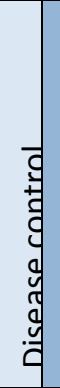 & $\frac{c}{2}$ & 起 & 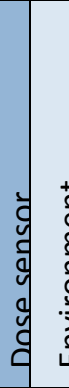 & 青: & 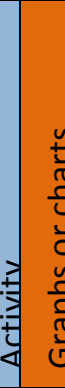 & 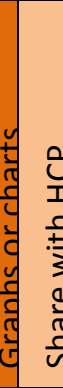 & $\begin{array}{l}3 \\
\frac{\pi}{0} \\
\frac{\pi}{4} \\
\frac{\pi}{4}\end{array}$ & 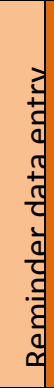 & 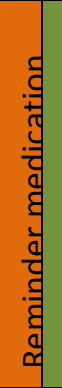 & $\frac{1}{x}$ & 욤 & का & 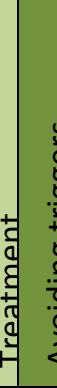 & & g & 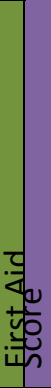 & \\
\hline \multicolumn{25}{|l|}{ ASTHMA } \\
\hline $\begin{array}{l}\text { Asthma } \\
\text { MD }\end{array}$ & $\begin{array}{c}\text { Mar } \\
10, \\
2017\end{array}$ & $\begin{array}{l}\text { Doctor (Dr. } \\
\text { Sam Pejham, } \\
\text { UCSF Medical } \\
\text { School Clinical } \\
\text { Faculty and } \\
\text { Director of Tri- } \\
\text { Valley } \\
\text { Pediatrics) }\end{array}$ & $\begin{array}{l}\text { 의 } \\
=0\end{array}$ & 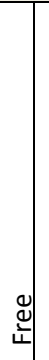 & 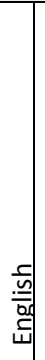 & $x$ & & \begin{tabular}{l|l}
$x$ & r
\end{tabular} & $x$ & & & $x$ & $x$ & $x$ & & $x$ & & & & & & & & 8 \\
\hline $\begin{array}{l}\text { Kiss my } \\
\text { asthma }\end{array}$ & $\begin{array}{c}\text { Aug } \\
01 \\
2017\end{array}$ & $\begin{array}{l}\text { Doctor } \\
\text { (University of } \\
\text { Syndney with } \\
\text { Asthma } \\
\text { Australia) }\end{array}$ & $\begin{array}{l}\text { 의 } \\
\frac{0}{0} \\
\frac{0}{0} \\
\frac{1}{4}\end{array}$ & | & $\frac{c}{\frac{c}{-n}}$ & $x$ & & & & & & $x$ & $x$ & & & $x$ & $x$ & & & $x$ & & $x$ & $x$ & 8 \\
\hline $\begin{array}{l}7 \text { keys to } \\
\text { manage } \\
\text { Child } \\
\text { Asthma }\end{array}$ & $\begin{array}{c}\text { Apr } \\
27 \\
2016\end{array}$ & $\begin{array}{l}\text { Doctor (Dr. } \\
\text { Jagdish } \\
\text { Chinnappa) }\end{array}$ & 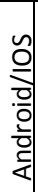 & $\mid$ & 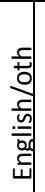 & $x$ & & & & & & $x$ & $x$ & $x$ & & $x$ & $x$ & & $x$ & $x$ & $\mathrm{x}$ & & & 8 \\
\hline $\begin{array}{l}\text { Conolly } \\
\text { Asthma } \\
\text { app }\end{array}$ & $\begin{array}{c}\text { May } \\
\text { 03, } \\
2015\end{array}$ & $\begin{array}{l}\text { Doctor } \\
\text { (Connolly } \\
\text { Hospital } \\
\text { Blanchardstow } \\
\text { n Respiratory } \\
\text { Department) } \\
\text { and Mechtech } \\
\text { (URXmobile } \\
\text { system) }\end{array}$ & $\begin{array}{l}\text { ñ } \\
\frac{0}{0} \\
\frac{0}{0} \\
\text { ? }\end{array}$ & 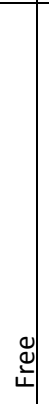 & 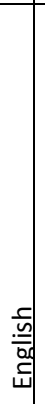 & $x$ & $x$ & $x$ & & & & $x$ & $x$ & $\mathrm{x}$ & & $x$ & $x$ & $x$ & $x$ & $x$ & $x$ & $x$ & $x$ & 8 \\
\hline $\begin{array}{l}\text { Advocad } \\
\text { e Asthma } \\
\text { Coach }\end{array}$ & $\begin{array}{c}\text { Sep } \\
20 \\
2016\end{array}$ & $\begin{array}{l}\text { Doctor } \\
\text { (Advocade } \\
\text { Health Care) }\end{array}$ & 으 & ֻ & $\frac{\bar{c}}{\frac{m}{\mathrm{~g}}}$ & $x$ & $x$ & $x$ & & & & $x$ & $x$ & $x$ & & $x$ & $x$ & $x$ & $x$ & $x$ & $x$ & $x$ & $x$ & 8 \\
\hline
\end{tabular}

This article is protected by copyright. All rights reserved. 


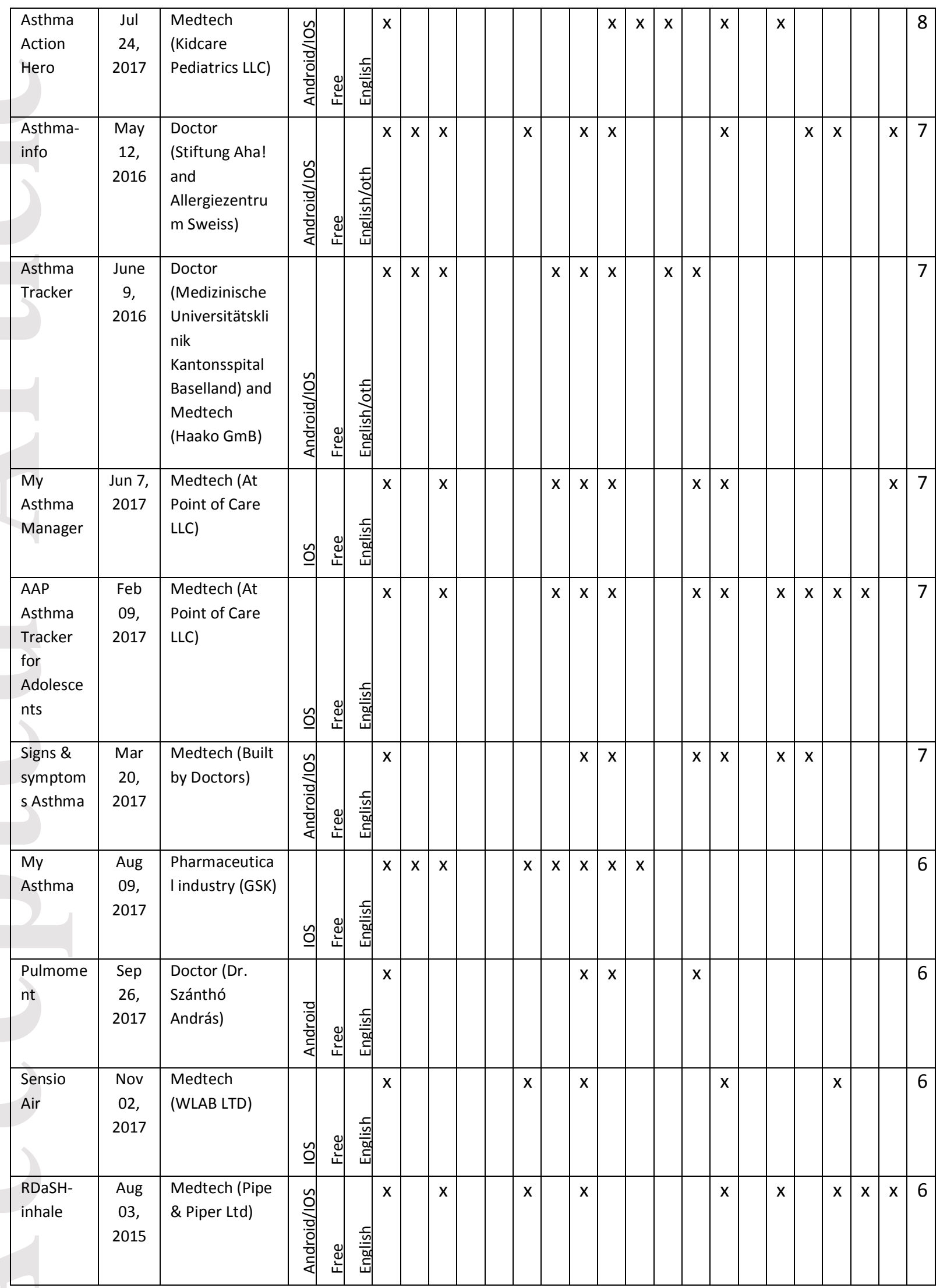

This article is protected by copyright. All rights reserved. 


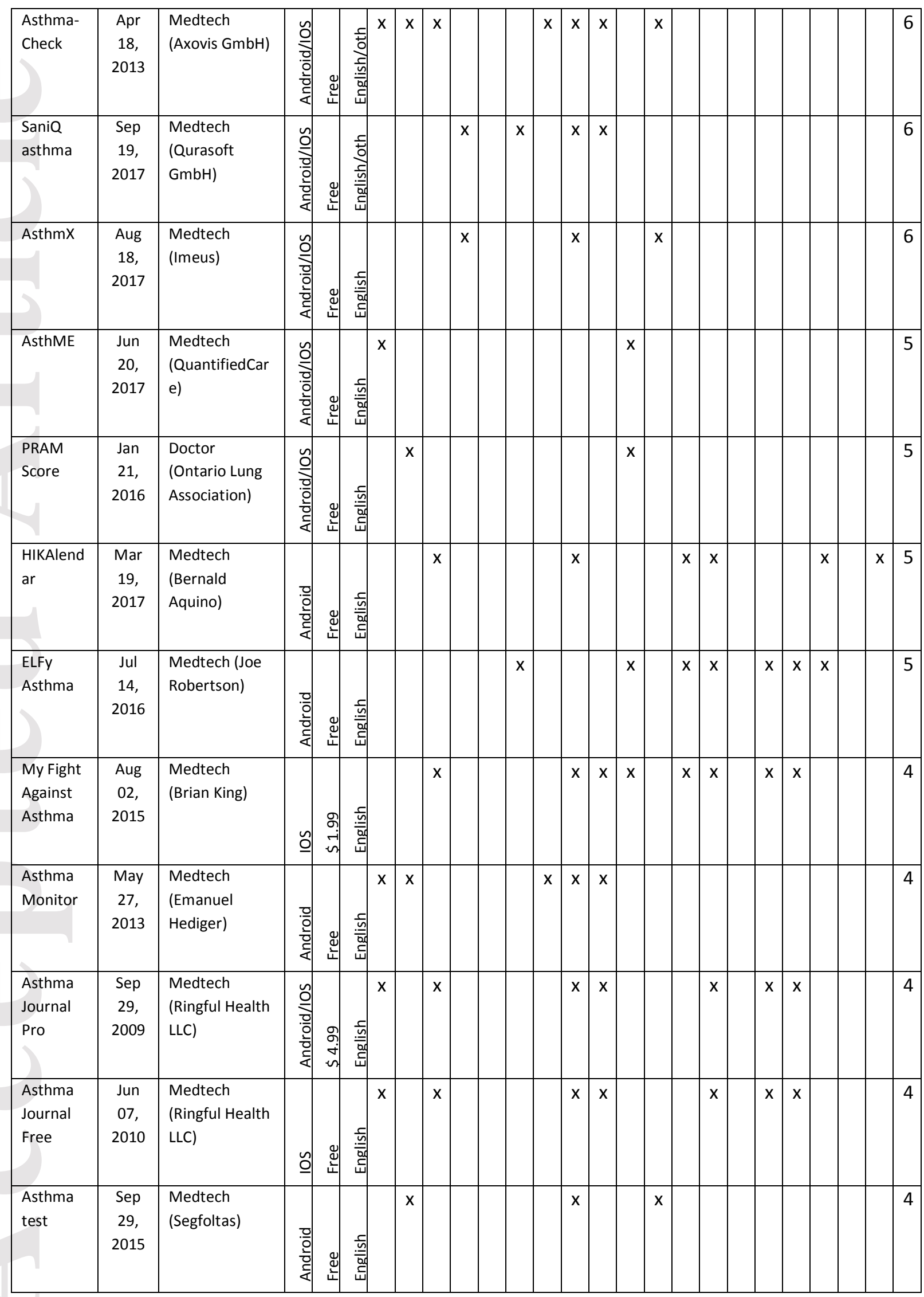

This article is protected by copyright. All rights reserved. 


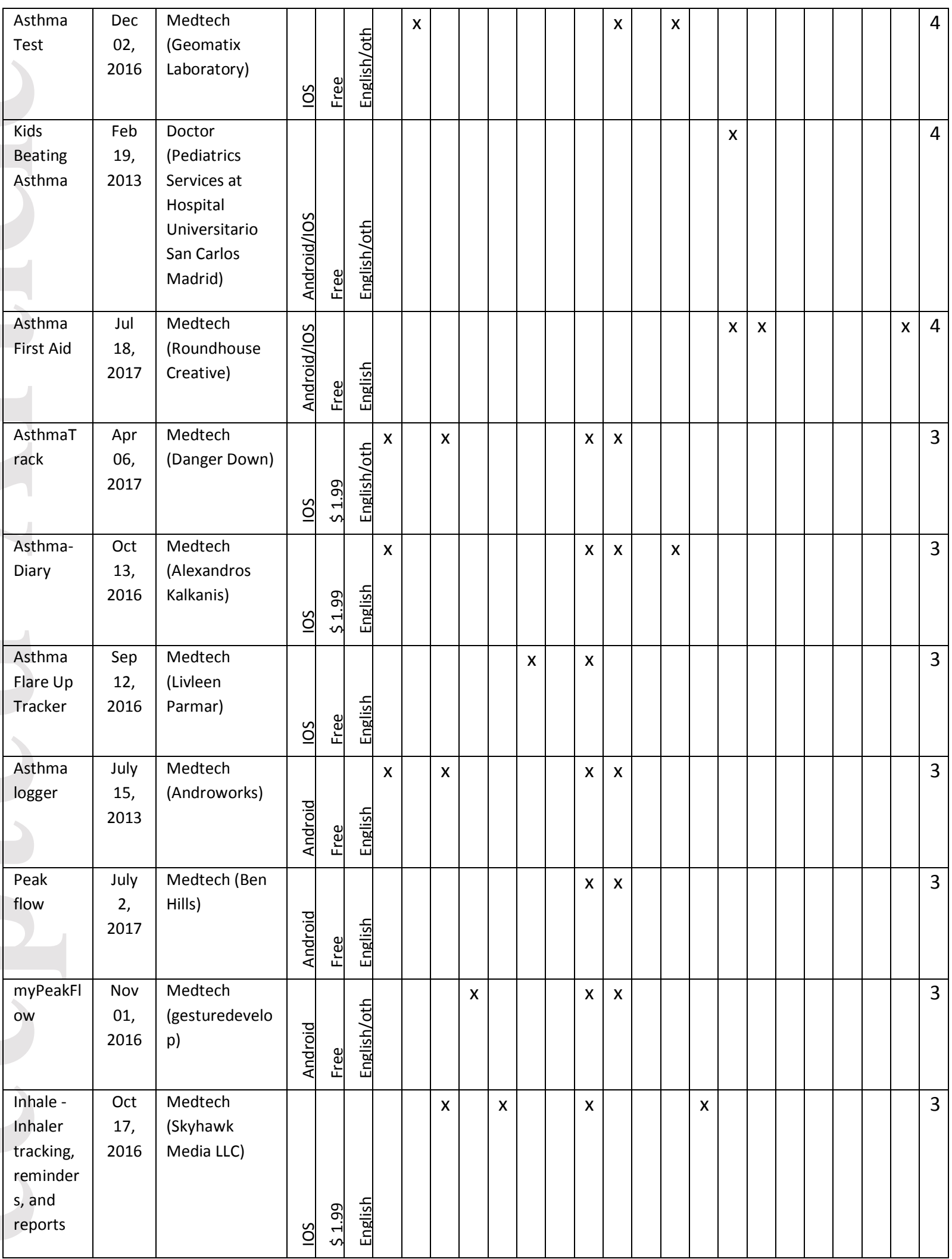

This article is protected by copyright. All rights reserved. 


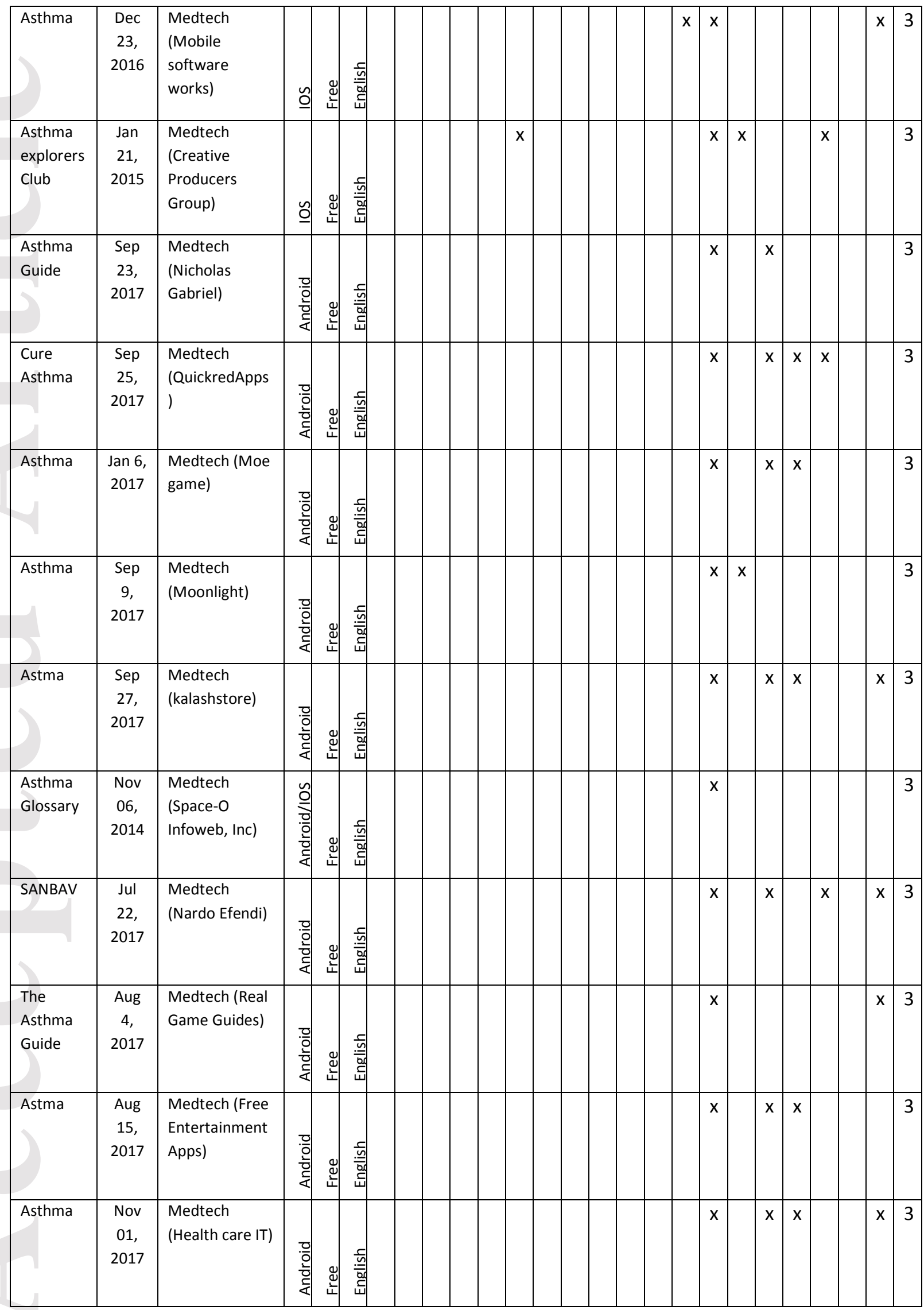

This article is protected by copyright. All rights reserved. 


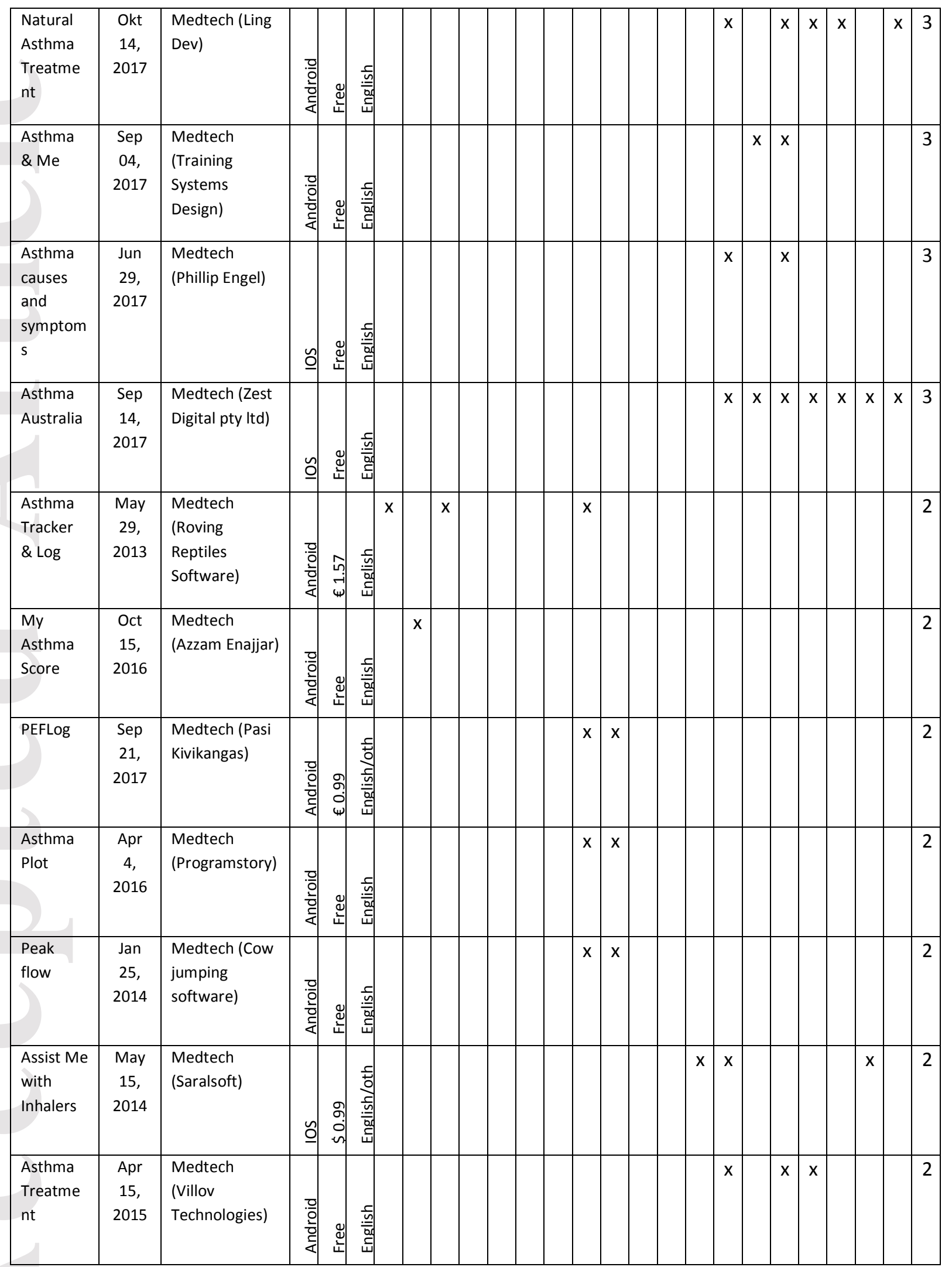

This article is protected by copyright. All rights reserved. 


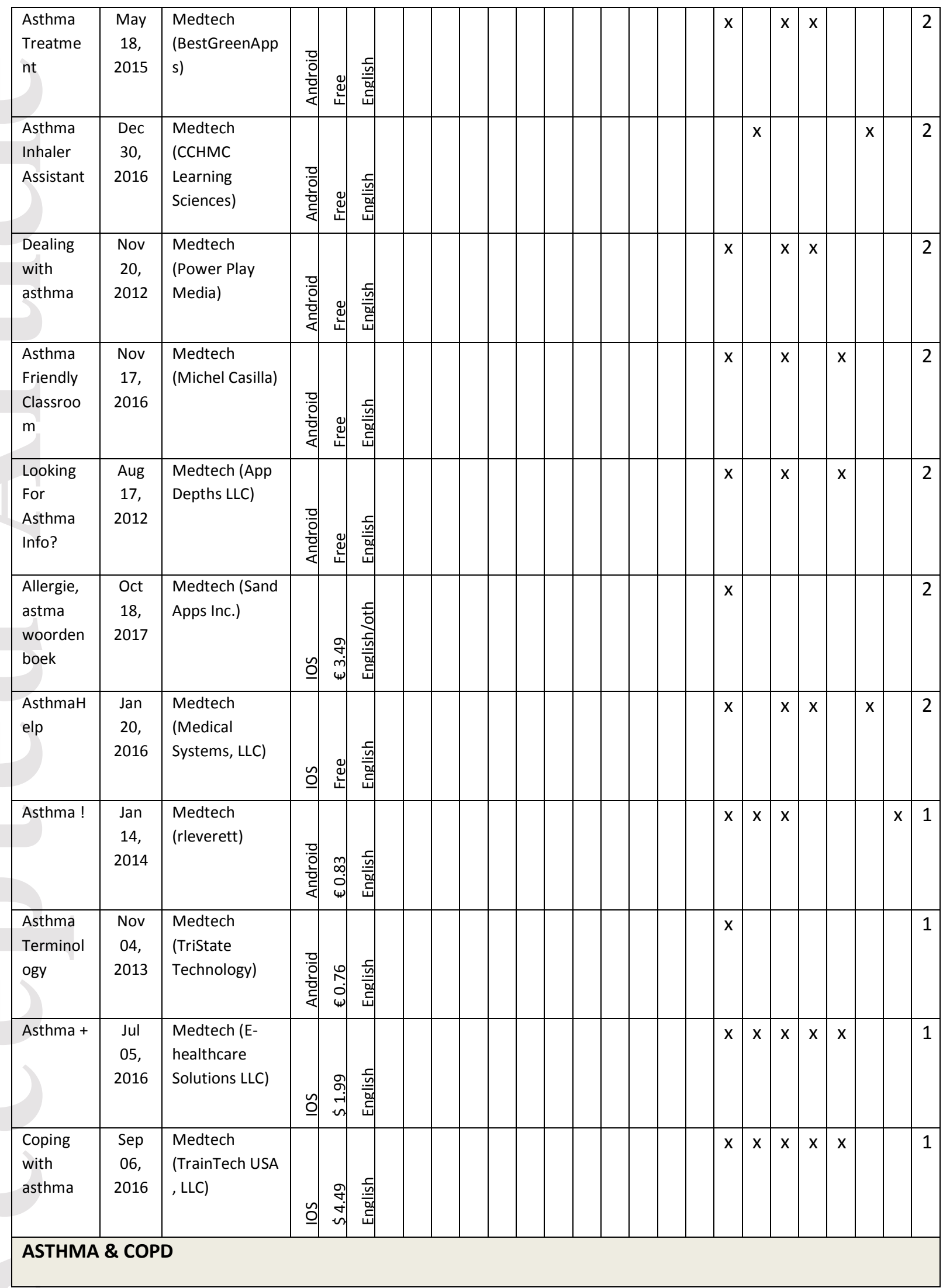

This article is protected by copyright. All rights reserved. 


\begin{tabular}{|c|c|c|c|c|c|c|c|c|c|c|c|c|c|c|c|c|c|c|c|c|c|c|c|}
\hline $\begin{array}{l}\text { Propeller } \\
\text { Health }\end{array}$ & $\begin{array}{c}\text { Oct } \\
02 \\
2017\end{array}$ & $\begin{array}{l}\text { Medtech } \\
\text { (Reciprocal } \\
\text { Labs) }\end{array}$ & $\begin{array}{l}\text { 일 } \\
\frac{0}{0} \\
\frac{0}{0} \\
\frac{0}{4}\end{array}$ & $\frac{9}{\frac{0}{4}}$ & 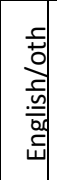 & $x$ & $x$ & $x$ & & $x$ & $x$ & $x$ & $x$ & & & $x$ & $x$ & & & & $x$ & & 8 \\
\hline Respitrack & $\begin{array}{c}\text { Mar } \\
29 \\
2016\end{array}$ & $\begin{array}{l}\text { Doctor (Vinay } \\
\text { Parab) }\end{array}$ & $\begin{array}{l}\text { 이 } \\
\frac{0}{0} \\
\frac{0}{0} \\
\frac{0}{4}\end{array}$ & $\frac{9}{4}$ & 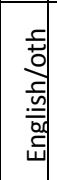 & $x$ & & $x$ & & & & $x$ & $x$ & & & $x$ & $x$ & & $x$ & $x$ & & & 7 \\
\hline $\begin{array}{l}\text { My } \\
\text { Breathefre } \\
\text { e }\end{array}$ & $\begin{array}{c}\text { Feb } \\
02 \\
2016\end{array}$ & $\begin{array}{l}\text { Medtech } \\
\text { (Cipla) }\end{array}$ & 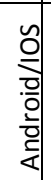 & $\frac{0}{4}$ & 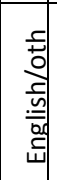 & & & & $x$ & & & $x$ & $x$ & $x$ & & $x$ & $x$ & $x$ & $x$ & $x$ & $x$ & $x$ & 7 \\
\hline CareTRx & $\begin{array}{c}\text { Mar } \\
29 \\
2017\end{array}$ & $\begin{array}{l}\text { Pharmaceutic } \\
\text { al industry } \\
\text { (Teva) }\end{array}$ & 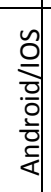 & $\frac{0}{4}$ & $\frac{\bar{n}}{\underline{\underline{m}}}$ & $x$ & & $x$ & & $x$ & & $x$ & $x$ & & & $x$ & & & & & & & 6 \\
\hline $\begin{array}{l}\text { BreatheS } \\
\text { mart CH- } \\
\text { OS }\end{array}$ & $\begin{array}{c}\text { Aug } \\
16, \\
2017\end{array}$ & $\begin{array}{l}\text { Medtech } \\
\text { (Cohero } \\
\text { Health) }\end{array}$ & 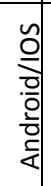 & $\frac{0}{4}$ & 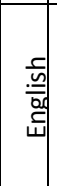 & & & $x$ & $x$ & $x$ & & $x$ & $x$ & & & $x$ & & & & & & & 6 \\
\hline $\begin{array}{l}\text { Smart } \\
\text { peak flow }\end{array}$ & $\begin{array}{c}\text { Jul } \\
25 \\
2017\end{array}$ & $\begin{array}{l}\text { Medtech } \\
\text { (Smart } \\
\text { Respiratory } \\
\text { Products) }\end{array}$ & $\begin{array}{l}\text { 일 } \\
\frac{0}{0} \\
\frac{0}{0} \\
\frac{0}{4}\end{array}$ & $\frac{0}{4}$ & 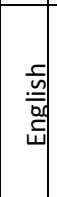 & & & & $x$ & & & $x$ & $x$ & & $x$ & & & & & & & & 6 \\
\hline $\begin{array}{l}\text { Smartinhal } \\
\text { er }\end{array}$ & $\begin{array}{c}\text { Oct } \\
31 \\
2017\end{array}$ & $\begin{array}{l}\text { Medtech } \\
\text { (Adherium } \\
\text { (NZ) Limited) }\end{array}$ & $\begin{array}{l}\text { 임 } \\
\frac{0}{0} \\
\frac{0}{0} \\
\frac{1}{4}\end{array}$ & $\frac{0}{4}$ & $\frac{\frac{n}{n}}{\frac{-n}{0}}$ & & & & & $x$ & & $x$ & & & & $x$ & & & & & & & 6 \\
\hline $\begin{array}{l}\text { MIR Smart } \\
\text { one }\end{array}$ & $\begin{array}{c}\text { Apr } \\
13 \\
2017\end{array}$ & $\begin{array}{l}\text { Medtech } \\
\text { (MIR srl - } \\
\text { Medical } \\
\text { International } \\
\text { Research) }\end{array}$ & $\begin{array}{l}\text { 의 } \\
\frac{7}{0} \\
\text { 흠 } \\
\frac{1}{4}\end{array}$ & $\frac{9}{4}$ & 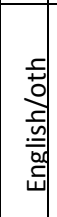 & $x$ & & & $x$ & & & $x$ & $x$ & & & & & & & & & & 5 \\
\hline $\begin{array}{l}\text { Wing by } \\
\text { sparo labs }\end{array}$ & $\begin{array}{c}\text { May } \\
20, \\
2017\end{array}$ & $\begin{array}{l}\text { Medtech } \\
\text { (Sparo Labs) }\end{array}$ & $\underline{\mathrm{o}}$ & $\frac{9}{4}$ & 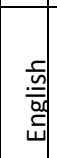 & $x$ & & $x$ & $x$ & $x$ & & $x$ & $x$ & & $x$ & $x$ & & & & & & & 5 \\
\hline $\begin{array}{l}\text { air smart } \\
\text { spiromete } \\
r\end{array}$ & $\begin{array}{c}\text { Okt } \\
13, \\
2017\end{array}$ & $\begin{array}{l}\text { Medtech } \\
\text { (NuvoAir AB) }\end{array}$ & $\begin{array}{l}\text { 임 } \\
\frac{0}{0} \\
\frac{0}{0} \\
\frac{0}{4}\end{array}$ & $\frac{8}{4}$ & 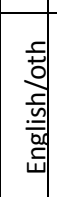 & & & & $x$ & & & $x$ & $x$ & & & & & & & & & & 5 \\
\hline $\begin{array}{l}\text { Breathcou } \\
\text { nt }\end{array}$ & $\begin{array}{c}\operatorname{Jan} 9, \\
2017\end{array}$ & $\begin{array}{l}\text { Medtech } \\
\text { (Segfoltas) }\end{array}$ & $\begin{array}{l}\text { 음 } \\
\frac{1}{0} \\
\text { 난 }\end{array}$ & $\frac{0}{4}$ & 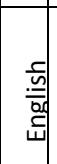 & & & & $x$ & & & $x$ & $x$ & & $x$ & & & & & & & & 5 \\
\hline
\end{tabular}

This article is protected by copyright. All rights reserved. 


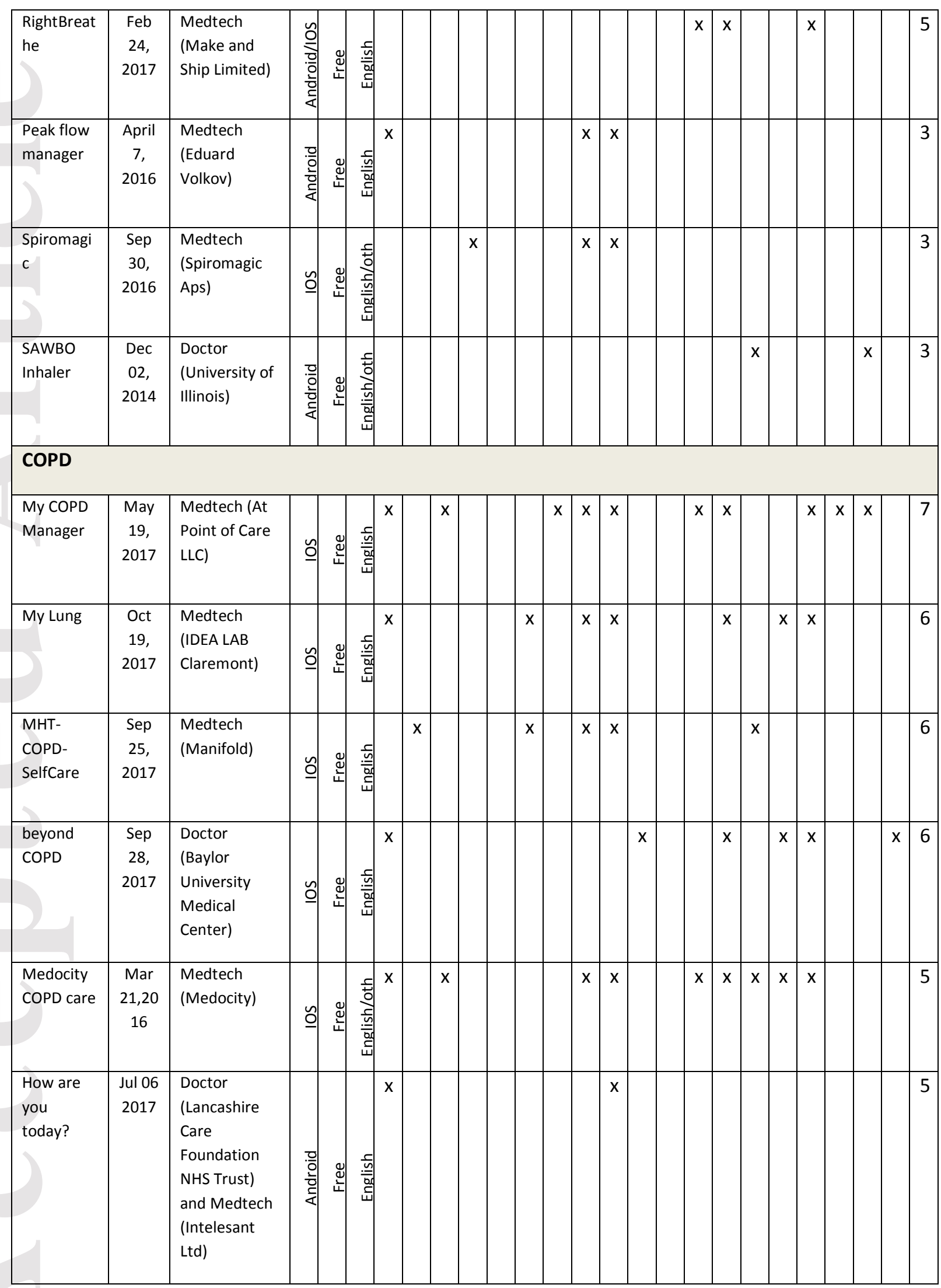

This article is protected by copyright. All rights reserved. 


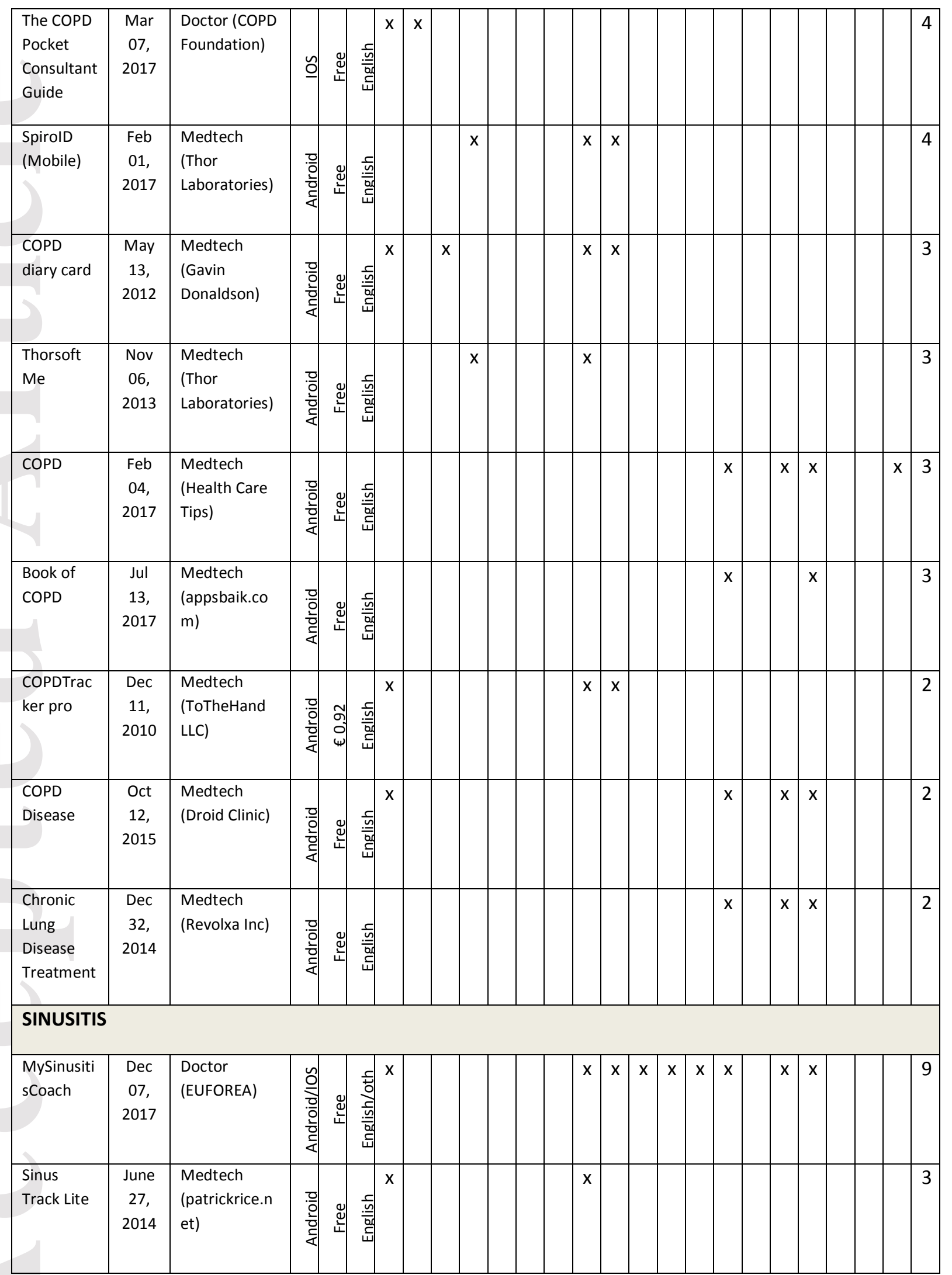

This article is protected by copyright. All rights reserved. 


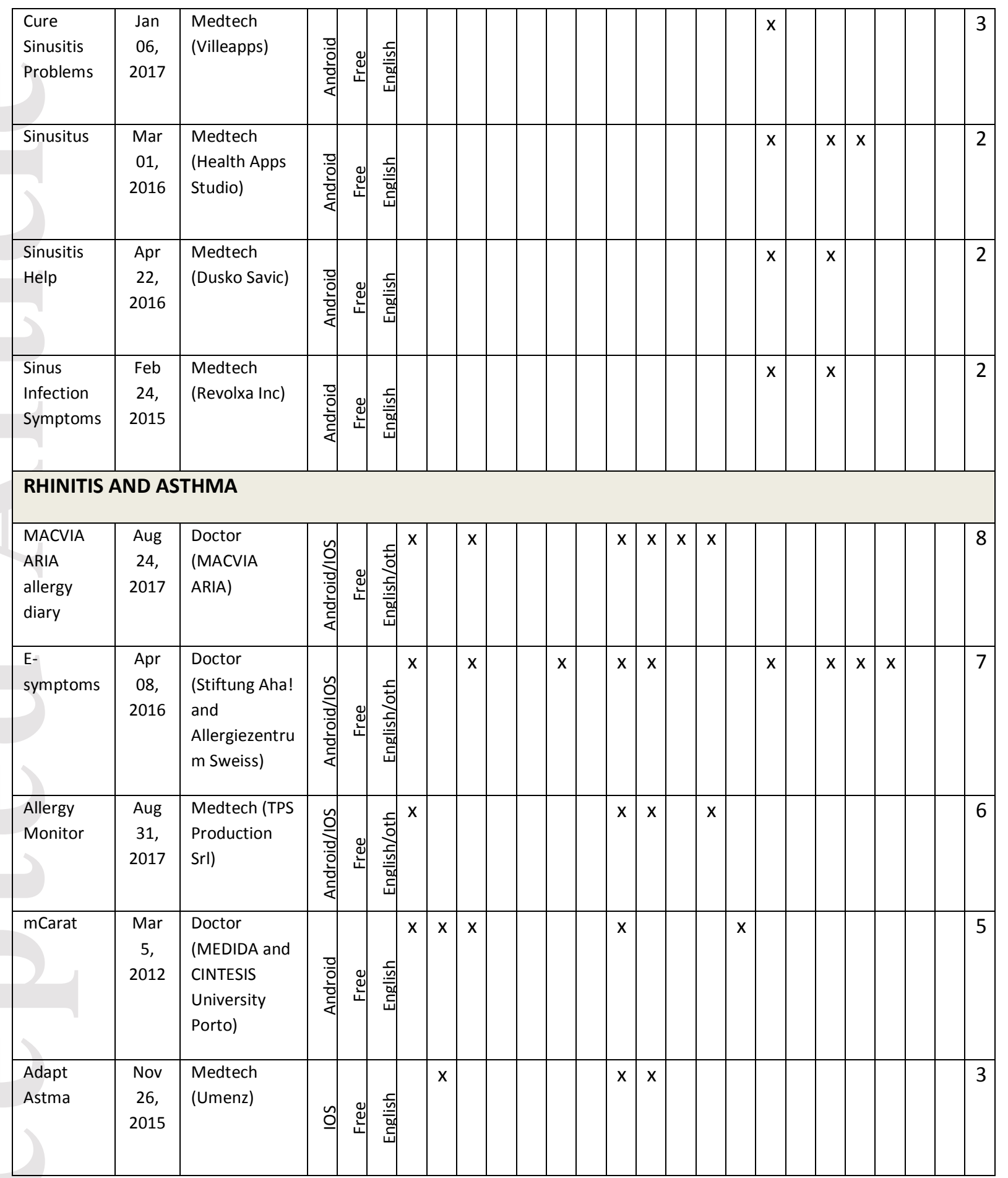

This article is protected by copyright. All rights reserved. 


\section{REFERENCES}

1. Johnson A. Biology for engineers. Boca Raton, FL: CRC Press; 2011.

2. Stephani V, Opoku D, Quentin W. A systematic review of randomized controlled trials of mHealth interventions against non-communicable diseases in developing countries. BMC Public Health. 2016;16:572.

3. Bousquet J, Chavannes NH, Guldemond N, Haahtela T, Hellings PW, Sheikh A. Realising the potential of mHealth to improve asthma and allergy care: how to shape the future. Eur Respir J. 2017;49(5).

4. Bravo P, Edwards A, Barr PJ, Scholl I, Elwyn G, McAllister M. Conceptualising patient empowerment: a mixed methods study. BMC Health Serv Res. 2015 Jul 1;15:252.

5. Hellings PW, Borrelli D, Pietikainen S, Agache I, Akdis C, Bachert C, et al. European Summit on the Prevention and Self-Management of Chronic Respiratory Diseases: report of the European Union Parliament Summit (29 March 2017). Clin Transl Allergy. 2017;7:49.

6. European Innovation Partnership on Active and Healthy Ageing APB, Mechanisms of the Development of Allergy W 10, Global Alliance against Chronic Respiratory Diseases, Bousquet J, Addis A, Adcock I, et al. Integrated care pathways for airway diseases (AIRWAYS-ICPs). Eur Respir J. 2014;44(2):304-23.

7. Bousquet J, Caimmi DP, Bedbrook A, Bewick M, Hellings PW, Devillier P, et al. Pilot study of mobile phone technology in allergic rhinitis in European countries: the MASK-rhinitis study. Allergy. 2017;72(6):857-65.

8. GREEN PAPER on mobile Health (mHealth). (Euopean Commission) [Internet]. Available from: https://ec.europa.eu/digital-single-market/en/news/green-paper-mobile-health-mhealth

9. Bousquet J, Dahl R, Khaltaev N. Global alliance against chronic respiratory diseases. Allergy. 2007;62(3):216-23.

10. Papi A, Brightling C, Pedersen SE, Reddel HK. Asthma. Lancet. 2018;391(10122):783-800.

11. Chung KF, Wenzel SE, Brozek JL, Bush A, Castro M, Sterk PJ, et al. International ERS/ATS guidelines on definition, evaluation and treatment of severe asthma. Eur Respir J. 2014;43(2):343-73.

12. Peters SP, Ferguson G, Deniz Y, Reisner C. Uncontrolled asthma: a review of the prevalence, disease burden and options for treatment. Respir Med. 2006;100(7):1139-51.

13. Dean BB, Calimlim BM, Kindermann SL, Khandker RK, Tinkelman D. The impact of uncontrolled asthma on absenteeism and health-related quality of life. J Asthma. 2009;46(9):861-6.

14. Chronic obstructive pulmonary disease (COPD). [Internet]. Available from: http://www.who.int/respiratory/copd/en/

15. Bousquet J, Hellings PW, Agache I, Bedbrook A, Bachert C, Bergmann KC, et al. ARIA 2016: Care pathways implementing emerging technologies for predictive medicine in rhinitis and asthma across the life cycle. Clin Transl Allergy. 2016;6:47.

16. Droessaert V, Timmermans M, Dekimpe E, Seys S, Ceuppens JJ, Fokkens WJ, et al. Real-life

This article is protected by copyright. All rights reserved. 
study showing better control of allergic rhinitis by immunotherapy than regular pharmacotherapy. Rhinology. 2016;54(3):214-20.

17. Colás C, Brosa M, Antón E, Montoro J, Navarro A, Dordal MT, et al. Estimate of the total costs of allergic rhinitis in specialized care based on real-world data: the FERIN Study. Allergy. 2017;72(6):959-66.

18. Fokkens WJ, Lund VJ, Mullol J, Bachert C, Alobid I, Baroody F, et al. European Position Paper on Rhinosinusitis and Nasal Polyps 2012. Rhinol Suppl. 2012 Mar;(23):3 p preceding table of contents, 1-298.

19. Tomassen P, Vandeplas G, Van Zele T, Cardell L-O, Arebro J, Olze H, et al. Inflammatory endotypes of chronic rhinosinusitis based on cluster analysis of biomarkers. J Allergy Clin Immunol. 2016;137(5):1449-1456.e4.

20. De Greve G, Hellings PW, Fokkens WJ, Pugin B, Steelant B, Seys SF. Endotype-driven treatment in chronic upper airway diseases. Clin Transl Allergy. 2017;7:22.

21. van der Veen J, Seys SF, Timmermans M, Levie P, Jorissen M, Fokkens WJ, et al. Real-life study showing uncontrolled rhinosinusitis after sinus surgery in a tertiary referral centre. Allergy. 2017;72(2):282-90.

22. Phillips KM, Hoehle LP, Bergmark RW, Campbell AP, Caradonna DS, Gray ST, et al. Chronic rhinosinusitis severity is associated with need for asthma-related systemic corticosteroids. Rhinology. 2017;55(3):211-7.

23. Funnell MM. Patient empowerment: What does it really mean? Patient Educ Couns. 2016;99(12):1921-2.

24. Pinnock H, Parke HL, Panagioti M, Daines L, Pearce G, Epiphaniou E, et al. Systematic meta-review of supported self-management for asthma: a healthcare perspective. BMC Med. 2017;15(1):64.

25. Gibson PG, Powell H, Coughlan J, Wilson AJ, Abramson M, Haywood P, et al. Selfmanagement education and regular practitioner review for adults with asthma. Cochrane Database Syst Rev. 2003;(1):CD001117.

26. Hui CY, Walton R, McKinstry B, Jackson T, Parker R, Pinnock H. The use of mobile applications to support self-management for people with asthma: a systematic review of controlled studies to identify features associated with clinical effectiveness and adherence. J Am Med Inform Assoc. 2017;24(3):619-32.

27. Licskai C, Sands TW, Ferrone M. Development and pilot testing of a mobile health solution for asthma self-management: asthma action plan smartphone application pilot study. Can Respir J. 2013;20(4):301-6.

28. Perry TT, Marshall A, Berlinski A, Rettiganti M, Brown RH, Randle SM, et al. Smartphonebased vs paper-based asthma action plans for adolescents. Ann Allergy Asthma Immunol. 2017;118(3):298-303.

29. Burbank AJ, Lewis SD, Hewes M, Schellhase DE, Rettiganti M, Hall-Barrow J, et al. Mobilebased asthma action plans for adolescents. J Asthma Off J Assoc Care Asthma. 2015;52(6):583-6.

This article is protected by copyright. All rights reserved. 
30. Alwashmi M, Hawboldt J, Davis E, Marra C, Gamble J-M, Abu Ashour W. The Effect of Smartphone Interventions on Patients With Chronic Obstructive Pulmonary Disease Exacerbations: A Systematic Review and Meta-Analysis. JMIR MHealth UHealth. 2016;4(3):e105.

31. Yang F, Wang Y, Yang C, Hu H, Xiong Z. Mobile health applications in self-management of patients with chronic obstructive pulmonary disease: a systematic review and meta-analysis of their efficacy. BMC Pulm Med. 2018;18(1):147.

32. McCabe C, McCann M, Brady AM. Computer and mobile technology interventions for selfmanagement in chronic obstructive pulmonary disease. Cochrane Database Syst Rev. 2017 23;5:CD011425.

33. Seys S, Bousquet J, Bachert C, Fokkens W, Agache I, Bernal-Sprekelsen M, et al. mySinusitisCoach: patient empowerment in chronic rhinosinusitis using mobile technology. Rhinology. 2018;56(3):209-215.

34. Bourret R, Bousquet J, Mercier J, Camuzat T, Bedbrook A, Demoly P, et al. MASK-rhinitis, a single tool for integrated care pathways in allergic rhinitis. World Hosp Health Serv. 2015;51(3):369.

35. Honkoop PJ, Simpson A, Bonini M, Snoeck-Stroband JB, Meah S, Fan Chung K, et al. MyAirCoach: the use of home-monitoring and mHealth systems to predict deterioration in asthma control and the occurrence of asthma exacerbations; study protocol of an observational study. BMJ Open. 2017;7(1):e013935.

36. Tran N, Coffman JM, Sumino K, Cabana MD. Patient reminder systems and asthma medication adherence: a systematic review. J Asthma Off J Assoc Care Asthma. 2014;51(5):536-43.

37. Pizzulli A, Perna S, Florack J, Pizzulli A, Giordani P, Tripodi S, et al. The impact of telemonitoring on adherence to nasal corticosteroid treatment in children with seasonal allergic rhinoconjunctivitis. Clin Exp Allergy J Br Soc Allergy Clin Immunol. 2014;44(10):1246-54.

38. Hamine S, Gerth-Guyette E, Faulx D, Green BB, Ginsburg AS. Impact of mHealth chronic disease management on treatment adherence and patient outcomes: a systematic review. J Med Internet Res. 2015;17(2):e52.

39. Stoyanov SR, Hides L, Kavanagh DJ, Zelenko O, Tjondronegoro D, Mani M. Mobile App Rating Scale: A New Tool for Assessing the Quality of Health Mobile Apps. JMIR MHealth UHealth. 2015;3(1):e27.

40. Stoyanov SR, Hides L, Kavanagh DJ, Wilson H. Development and Validation of the User Version of the Mobile Application Rating Scale (uMARS). JMIR MHealth UHealth. 2016;4(2):e72.

41. Simpson AJ, Honkoop PJ, Kennington E, Snoeck-Stroband JB, Smith I, East J, et al. Perspectives of patients and healthcare professionals on mHealth for asthma self-management. Eur Respir J. 2017;49(5).

42. Voncken-Brewster V, Tange H, de Vries H, Nagykaldi Z, Winkens B, van der Weijden T. A randomized controlled trial evaluating the effectiveness of a web-based, computer-tailored selfmanagement intervention for people with or at risk for COPD. Int J Chron Obstruct Pulmon Dis. 2015;10:1061-73.

This article is protected by copyright. All rights reserved. 
43. Tabak M, Brusse-Keizer M, van der Valk P, Hermens H, Vollenbroek-Hutten M. A telehealth program for self-management of COPD exacerbations and promotion of an active lifestyle: a pilot randomized controlled trial. Int J Chron Obstruct Pulmon Dis. 2014;9:935-44.

44. Huckvale K, Morrison C, Ouyang J, Ghaghda A, Car J. The evolution of mobile apps for asthma: an updated systematic assessment of content and tools. BMC Med. 2015;13:58.

45. Medical device stand-alone software including apps [Internet]. Available from: https://www.gov.uk/government/uploads/system/uploads/attachment_data/file/648465/Software_flow _chart_Ed_1-04.pdf

46. Rumbold JMM, Pierscionek B. The Effect of the General Data Protection Regulation on Medical Research. J Med Internet Res. 2017;19(2):e47.

47. Sunyaev A, Dehling T, Taylor PL, Mandl KD. Availability and quality of mobile health app privacy policies. J Am Med Inform Assoc. 2015;22(e1):e28-33.

48. Code of Conduct on privacy for mHealth apps has been finalized [Internet]. Available from: https://ec.europa.eu/digital-single-market/en/news/code-conduct-privacy-mhealth-apps-has-beenfinalised

49. Wang J, Wang Y, Wei C, Yao NA, Yuan A, Shan Y, et al. Smartphone interventions for longterm health management of chronic diseases: an integrative review. Telemed J E-Health. 2014;20(6):570-83.

50. Con D, De Cruz P. Mobile Phone Apps for Inflammatory Bowel Disease Self-Management: A Systematic Assessment of Content and Tools. JMIR MHealth UHealth. 2016;4(1):e13.

51. Whitehead L, Seaton P. The Effectiveness of Self-Management Mobile Phone and Tablet Apps in Long-term Condition Management: A Systematic Review. J Med Internet Res. 2016;18(5):e97.

This article is protected by copyright. All rights reserved. 


\section{Conflict of interest statement}

Jean Bousquet is the Director of the Fondation FMC VIA-LR that owns the Allergy Diary mobile application and has shares in Kyomed-Innov. Peter Hellings and Jean Bousquet are part of the executive board of EUFOREA that owns the mySinusitisCoach mobile application. Sven Seys and Benoit Pugin are employees of EUFOREA that owns the mySinusitisCoach mobile application.

\section{Author contribution}

KS, SFS and PH conceived and designed the entire manuscript; KS, SFS and SG wrote the manuscript; JB, WJF, BP and PWJ critically reviewed and revised the manuscript. All authors read and approved the final manuscript.

This article is protected by copyright. All rights reserved. 


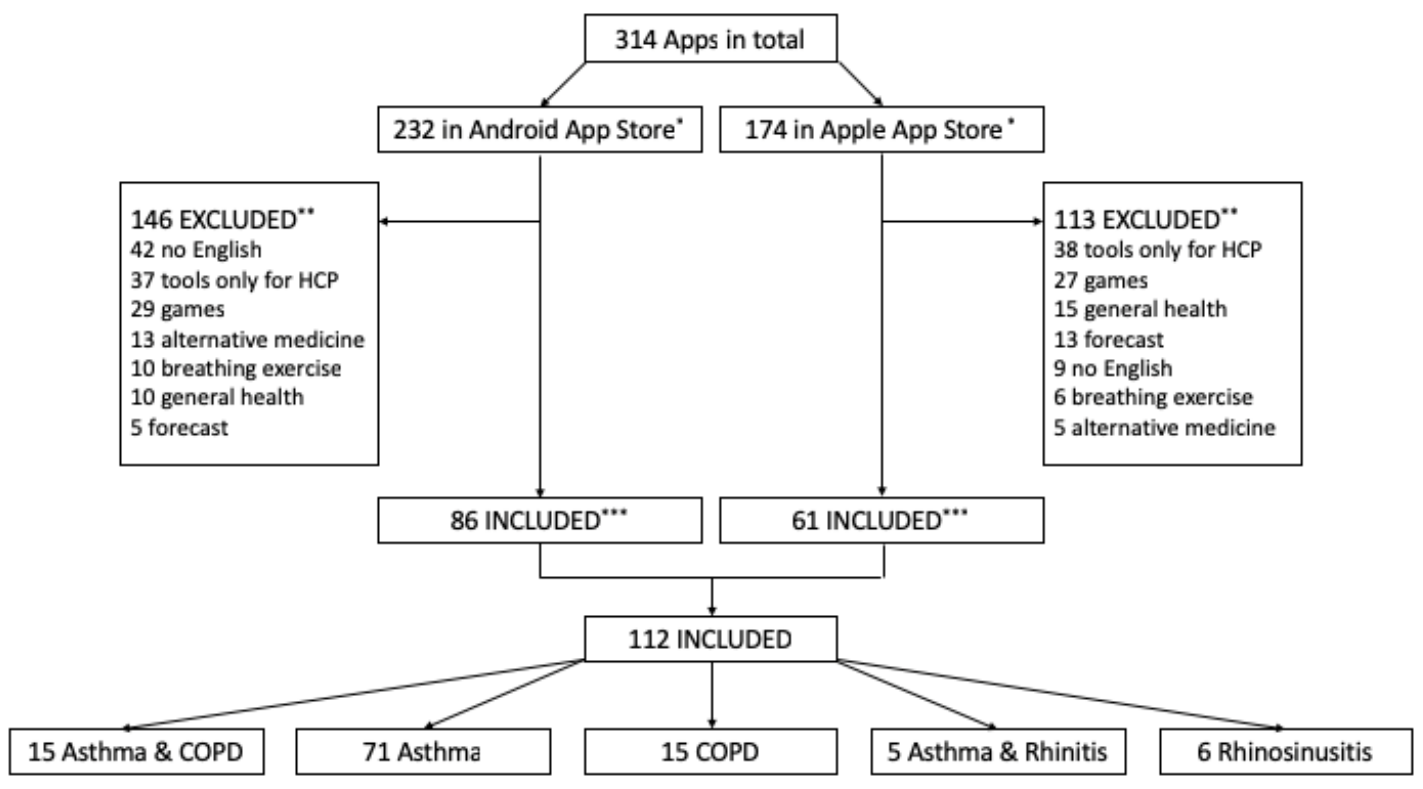

This article is protected by copyright. All rights reserved. 
A.

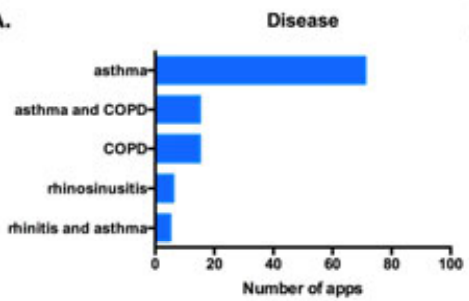

D.

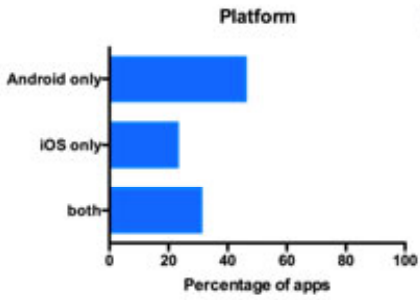

B.

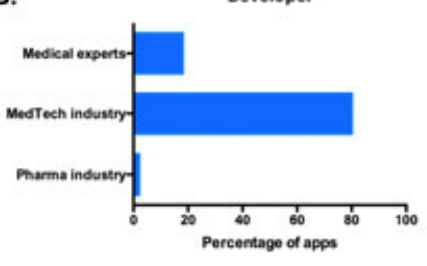

E.

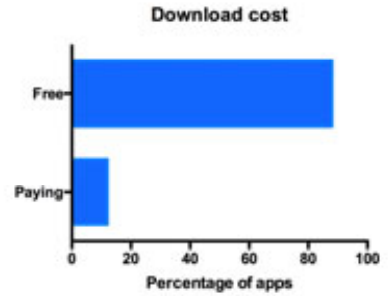

c.

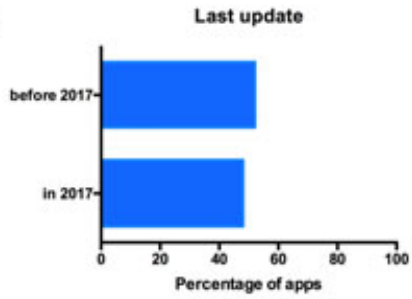

F.

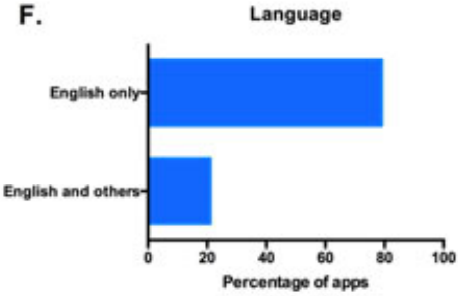

This article is protected by copyright. All rights reserved. 
A.

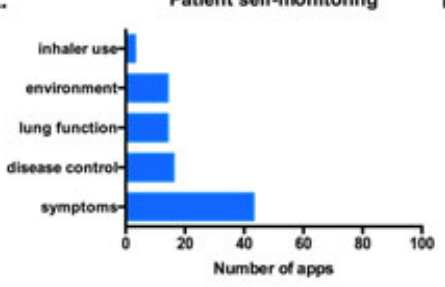

B.

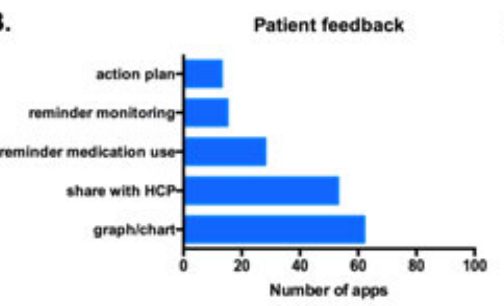

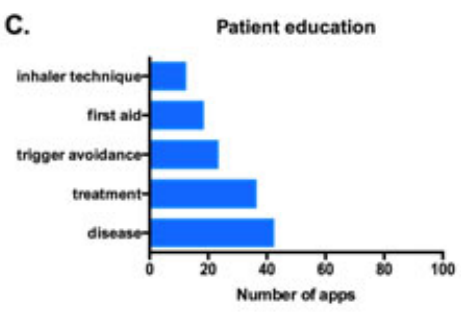

This article is protected by copyright. All rights reserved. 


\section{Patient empowerment through mobile technology index}

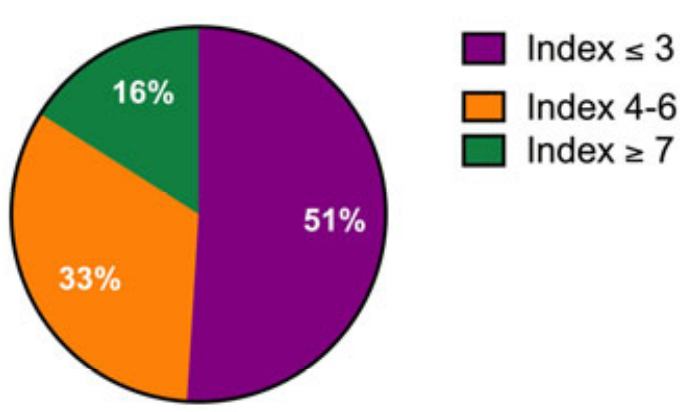

\section{TOP 3 of each disease area}

Asthma

1. Asthma MD

2. Kiss my asthma

3. My Asthma Manager

Index

8
7

COPD

1. My COPD Manager

2. My Lung

3. MHT-COPD-Selfcare

7

Asthma and COPD

1. Propeller Health

2. Respitrack

3. My Breathefree

8

Rhinitis and asthma

1. MACVIA ARIA Allergy Diary

2. E-symptoms

3. Allergy Monitor

Rhinosinusitis

1. mySinusitisCoach

2. Sinus Track Lite

3. Cure Sinusitis Problems

This article is protected by copyright. All rights reserved. 